\title{
Safety and tolerability of zoledronic acid and other bisphosphonates in osteoporosis management
}

This article was published in the following Dove Press journal:

Drug, Healthcare and Patient Safety

18 August 2010

Number of times this article has been viewed

\author{
Luca Dalle Carbonare \\ Mirko Zanatta \\ Adriano Gasparetto \\ Maria Teresa Valenti \\ Clinic of Internal Medicine D, \\ Department of Medicine, University \\ of Verona, Italy
}

\begin{abstract}
Bisphosphonates (BPs) are widely used in the treatment of postmenopausal osteoporosis and other metabolic bone diseases. They bind strongly to bone matrix and reduce bone loss through inhibition of osteoclast activity. They are classified as nitrogen- and nonnitrogen-containing bisphosphonates (NBPs and NNBPs, respectively). The former inhibit farnesyl diphosphate synthase while the latter induce the production of toxic analogs of adenosine triphosphate. These mechanisms of action are associated with different antifracture efficacy, and NBPs show the most powerful action. Moreover, recent evidence indicates that NBPs can also stimulate osteoblast activity and differentiation. Several randomized control trials have demonstrated that NBPs significantly improve bone mineral density, suppress bone turnover, and reduce the incidence of both vertebral and nonvertebral fragility fractures. Although they are generally considered safe, some side effects are reported (esophagitis, acute phase reaction, hypocalcemia, uveitis), and compliance with therapy is often inadequate. In particular, gastrointestinal discomfort is frequent with the older daily oral administrations and is responsible for a high proportion of discontinuation. The most recent weekly and monthly formulations, and in particular the yearly infusion of zoledronate, significantly improve persistence with treatment, and optimize clinical, densitometric, and antifracture outcomes.
\end{abstract}

Keywords: bisphosphonates, osteoporosis, safety, tolerability, zoledronic acid

\section{Introduction}

Bisphosphonates (BPs), synthetic analogs of the endogenous bone mineralization regulator pyrophosphate, are the most commonly used drugs in the treatment of postmenopausal osteoporosis (PO) and metabolic bone disease (MBD, such as bone loss induced by hormone suppressive therapy or glucocorticoids). BPs have been associated with significant improvement in bone mineral density (BMD), suppression of bone turnover, and reduction of fracture incidence. Fractures are the most important cause of morbidity and mortality among patients with MBD, and reduction of fracture risk is the main goal of treatment. ${ }^{1-4}$

BPs have been known for more than a century, and were initially used in toothpaste or to soften hard water. Nowadays, they are widely used in the treatment of skeletal diseases and are usually classified into two classes, ie, nitrogen- and non-nitrogencontaining bisphosphonates (NBPs and NNBPs, respectively).

All bisphosphonates reduce osteoclast activity, but NBPs (alendronate, risedronate, ibandronate, zoledronate) specifically inhibit farnesyl diphosphate synthase and block prenylation of guanosine triphosphate-binding protein, although other mechanisms of action have been recently identified. ${ }^{5}$ In contrast, NNBPs (etidronate, clodronate), 
the older molecules, induce the production of toxic analogs of adenosine triphosphate. The antifracture effect is also dependent on the different affinity of each type of molecule for the bone mineral matrix and in this respect the NBPs show the most powerful action.

There are various BP formulations and dosages. NBPs were initially administered orally once daily (alendronate $10 \mathrm{mg}$ and risedronate $5 \mathrm{mg}$ ), then weekly (risedronate $35 \mathrm{mg}$ and alendronate $70 \mathrm{mg}$ ), monthly (risedronate and ibandronate $150 \mathrm{mg}$ ), and, more recently, intravenous formulations have been developed (ibandronate $3 \mathrm{mg}$ every 3 months and zoledronate $5 \mathrm{mg}$ yearly). Adherence to treatment was quite difficult with daily dosages, mainly due to gastrointestinal (GI) intolerance, ${ }^{6}$ which is clinical important because poor compliance compromises treatment efficacy, and increases fracture incidence and medical costs. ${ }^{7}$

Compliance has been significantly increased with more recent weekly and monthly formulations, ${ }^{6}$ and particularly with intravenous yearly administration, which also improves clinical, densitometric, and antifracture outcomes. ${ }^{8,9}$

This review summarizes the pharmacologic properties, efficacy, tolerability, and safety of the most common and effective NBPs in the treatment of PO and MBD.

\section{Pharmacokinetic and pharmacodynamic profiles}

BPs are analogs of inorganic pyrophosphate, and composed of an enzyme-resistant phosphorus-carbon-phosphorus (P-C-P) structure able to adhere strongly to hydroxyapatite crystals (Figure 1). They have a relatively simple core structure, and the pharmacologic properties of each BP molecule depend on lateral chains, named R1 and R2 ${ }^{8}$ The P-C-P nucleus and $\mathrm{R} 1$ lateral chain are responsible for anchoring the drug to the bone mineral matrix, while R2 has biologic and therapeutic actions. The presence of a hydroxyl group in R1 markedly increases BP affinity for the bone matrix, while the nitrogen atom in R2 is responsible for antiresorptive potency. ${ }^{5}$

BPs are characterized by low GI absorption after oral administration, high affinity for bone matrix, urinary elimination, and long persistence on the bone surface. ${ }^{10}$ To increase intestinal absorption, BPs must be taken on an empty stomach, with water, at least 30-45 minutes before eating. This problem is obviously avoided using intravenous formulations.

Plasma half-life is very short, and BPs are cleared from plasma in about six hours; $50 \%$ of the absorbed drug adheres to the bone surface, while the remainder is excreted unchanged in urine. ${ }^{11}$ BPs persist in bone for a long time. For example, the effect of alendronate in humans is maintained for many years after discontinuation of prolonged treatment. ${ }^{1,12,13}$ The time that a BP resides within the skeleton, which is important for its biologic actions, is determined by three critical factors; firstly, the rate of bone remodeling in the host (faster remodeling means a shorter half-life), secondly, the side chain that, as mentioned above, greatly influences BP affinity for bone matrix, and, finally, the amount of drug reaching bone. For example, intravenous administration increases the speed and amount of drug reaching the bone and also the urinary system where the drug is eliminated; on the other hand, oral administrations have the problem of low intestinal absorption, with only a small portion of each single dose administered being able to reach the bone matrix.

BPs bind to plasma proteins and are eliminated by the kidney. ${ }^{11}$ They are not metabolized by the liver, and no other metabolites have been found in serum. Drug interactions are very few and they relate mainly to impaired oral absorption if they are administered concomitantly with other drugs or food. ${ }^{14}$ Some cases of hypocalcemia have been observed during treatment with aminoglycoside antibiotics. ${ }^{15}$

Due to their strong affinity for the skeleton, BPs are used in many skeletal diseases in addition to OP, including Paget's disease of bone, osteogenesis imperfecta, malignant hypercalcemia, metastatic cancer, and fibrous dysplasia. Dose and frequency of BP administration depend on the characteristics of each compound and on the type of disease being treated.

The therapeutic effect of BPs is mediated mainly by the inhibition of osteoclastic bone resorption, as demonstrated in bone biopsies, where fewer numbers of osteoclasts and lower bone erosion rates have been observed. ${ }^{12}$ Once embedded on the bone surface, BPs are slowly released into the bone matrix where they affect osteoclasts by reducing their differentiation, recruitment, and activity. In fact, it is believed that BPs are taken up by osteoclasts during bone resorption and, under their influence, osteoclasts lose their ruffled border and their normal cytoskeleton structure. ${ }^{12,17}$

NBPs (eg, alendronate, risedronate, ibandronate, zoledronate) interfere with protein prenylation by inhibiting farnesyl pyrophosphate (FPP) synthase, thereby reducing geranylgeranyl diphosphate metabolites involved in the mevalonate pathway. Inhibition of this pathway prevents posttranslational prenylation of small guanosine triphosphate-binding proteins (eg, Ras, Rho, and Rac), which regulate osteoclast morphology, cytoskeletal arrangement, membrane ruffling and trafficking, and lead to reduced resorptive activity and accelerated apoptosis (programmed cell death). ${ }^{18,19}$ Some authors have suggested that osteoclast 
<smiles>O=P(O)(O)OP(=O)(O)O</smiles>

Pyrophosphate<smiles>[R]C([R])(P(=O)(O)O)P(=O)(O)O</smiles>

Bisphosphonate<smiles>NCCCC(CO)(P(=O)(O)O)P(=O)(O)O</smiles>

Alendronate

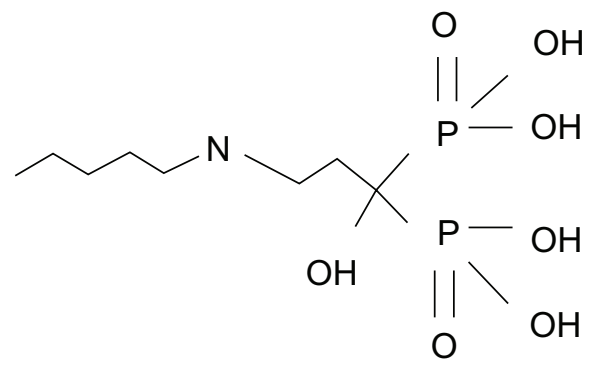

Ibandronate<smiles>O=P(O)(O)C(O)(CCC1=CCN=CC1)P(=O)(O)O</smiles>

Risedronate

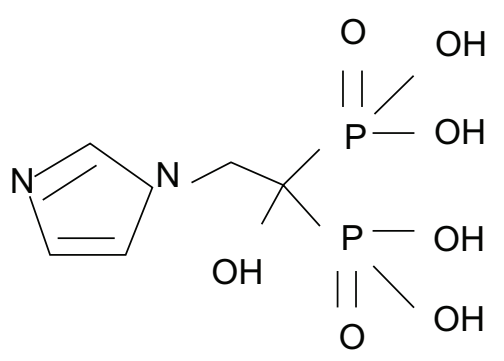

Zoledronate

Figure I Molecular structure of pyrophosphate and of the most common nitrogen-containing bisphosphonates.

inhibition by NBPs could also be osteoblast-mediated via the production of an inhibitory factor not yet characterized. ${ }^{20}$

Moreover, increasing evidence indicates that osteoblast activity could be directly stimulated by NBPs. Histomorphometric analysis in osteoporotic patients indicates that BPs may increase the mean wall thickness and reduce the imbalance between formation and resorption at the basic multicellular unit, ${ }^{16,21}$ leading to a continuing increase in BMD even after a long period of treatment, as demonstrated in clinical studies. ${ }^{1,16}$

NBPs also control osteoblastic proliferation and differentiation, ${ }^{22}$ modulate osteoblast production of extracellular matrix proteins, regulate the secretion of several cytokines and growth factors, and enhance proliferation and maturation of bone marrow stromal cells into the osteoblastic lineage. ${ }^{23}$ In addition, NBPs are able to prevent glucocorticoid-induced apoptosis of osteoblasts and osteocytes. ${ }^{24}$ The mechanism by which BPs stimulate osteoblasts is not completely understood. A type of anabolic effect has been associated with the stimulation of b-FGF. ${ }^{25}$ The involvement of bone morphogenetic protein $2^{26}$ has been postulated, including a cascade of osteoblast-related genes like RUNX2, Type 1 collagen, and bone sialoproteins. The OPG/RANKL system has been shown to be upregulated and significantly increased in bone marrow stromal cells after NBP treatment. ${ }^{23,27}$ We 
have also recently observed (Dalle Carbonare, unpublished data) an upregulation of Cox-2 expression in osteoblasts after NBP treatment, indicating a possible role of exogenous and endogenous prostaglandins, known to be involved in bone formation and remodelling. ${ }^{28}$

\section{Mechanism of action of zoledronic acid}

Zoledronic acid is an NBP and, like the other molecules of this class, binds to hydroxyapatite in the bone mineral matrix and strongly inhibits bone resorption. The ability of BPs to persist in bone matrix and to reduce osteoclast activity depends on their affinity for the bone matrix and potency of the inhibition of FPP. ${ }^{18}$ Zoledronic acid has the highest affinity for bone, followed by alendronate, ibandronate, risedronate, etidronate, and clodronate and it also alters mineral-surface properties, allowing greater adsorption. These properties are believed to contribute to its prolonged action. $^{29}$

The potency of zoledronic acid appears to be related also to its unique chemical structure. All BPs have a P-C-P nucleus that acts as a bone hook, while R2 is the structure primarily responsible for antiresorptive potency and duration of action. R2 in zoledronic acid is composed of a heterocyclic ring containing two nitrogen atoms (Figure 1). ${ }^{29,30}$ Biochemical assays have demonstrated the antiresorptive potency of this bisphosphonate. In in vitro analysis of FPP synthase inhibition, zoledronic acid was the most potent BP evaluated, followed by risedronate, ibandronate, alendronate, and pamidronate ${ }^{31}$ (Figure 2). The ability to inhibit FPP is directly correlated with effectiveness in suppressing bone turnover in vivo.

As already mentioned, the bioavailability of the BPs is very low when they are administered orally, but this problem is avoided by intravenous administration, such as with the yearly formulation of zoledronic acid. Orally administered BPs have shown approximately $1 \%$ bioavailability, whereas intravenous formulations have shown 100\% bioavailability.

Like the other BPs, zoledronic acid is eliminated rapidly in the urine, and studies of its endogenous metabolism have shown that it does not inhibit human cytochrome activity in vitro, in particular the p450 enzyme, or undergo biotransformation in vivo, indicating that it is not extensively metabolized. ${ }^{32-34}$

\section{Bone turnover markers}

Serum and urinary markers of bone metabolism are important biochemical tests in daily clinical practice for evaluation of
$\mathrm{PO}$ and MBD. The most common bone resorption markers are serum C-terminal collagen telopeptide, urinary N-terminal collagen telopeptide, and deoxypyridinoline, and for bone formation are alkaline phosphatase (ALP) and its bone isoenzyme (B-ALP) and osteocalcin. ${ }^{35}$ Patients with high bone turnover may have a higher risk of fracture than those with low bone turnover, independently of BMD. ${ }^{36}$

These bone markers are characterized by high biologic variability, and newer markers, such as serum RANKL, as well as genetic abnormalities of osteoblastic differentiation from mesenchymal precursors, are now under evaluation but, even if these are apparently more reliable, they are not still accessible in routine clinical practice. ${ }^{37,38}$

Bisphosphonates are potent inhibitors of bone turnover and significantly decrease both resorption and formation markers. ${ }^{12,13}$ Bone markers could be used to assess treatment compliance, efficacy, and disease activity. ${ }^{35,39}$

Inhibition of bone turnover in PO is similar for all the oral formulations of bisphosphonates (50\%-70\%), with a nadir after 6-12 months of treatment, and thereafter returning back to the premenopausal range. ${ }^{40-42}$ Inhibition of bone turnover is maintained for the duration of treatment and tends to persist even after discontinuation in terms of drug accumulation on the bone surface and slow release during osteoclastic activity. ${ }^{1,12,13,43}$ Of all the NBPs, risedronate seems to show the most rapid return to pretreatment levels (6-12 months). ${ }^{44}$

After a single intravenous dose of zoledronate, bone turnover marker reduction reaches up to $80 \%$ after 1 month and persists over the following 12 months. ${ }^{9,45,46}$ This is due to the high potency and affinity of zoledronic acid for hydroxyapatite and the $100 \%$ bioavailability afforded by the intravenous infusion. ${ }^{29,30}$

Excessive inhibition of bone turnover has been suggested to occur with prolonged treatment and has been considered potentially responsible for so-called "adynamic" bone disease. ${ }^{47}$ Until now, there has not been any convincing evidence of such a problem, and the long-term efficacy and safety of NBPs are maintained, as demonstrated by the data collected for 10 years of alendronate and 7 years for risedronate. ${ }^{1,43,48}$

\section{Safety and tolerability}

Bisphosphonates are widely used in $\mathrm{PO}$ and $\mathrm{MBD}$, and are usually well tolerated. Common side effects have been described, including GI intolerance, in particular esophagitis, as well as acute phase reaction and uveitis. These side effects are similar for all the molecules available, but some of them are correlated with their route of administration. 


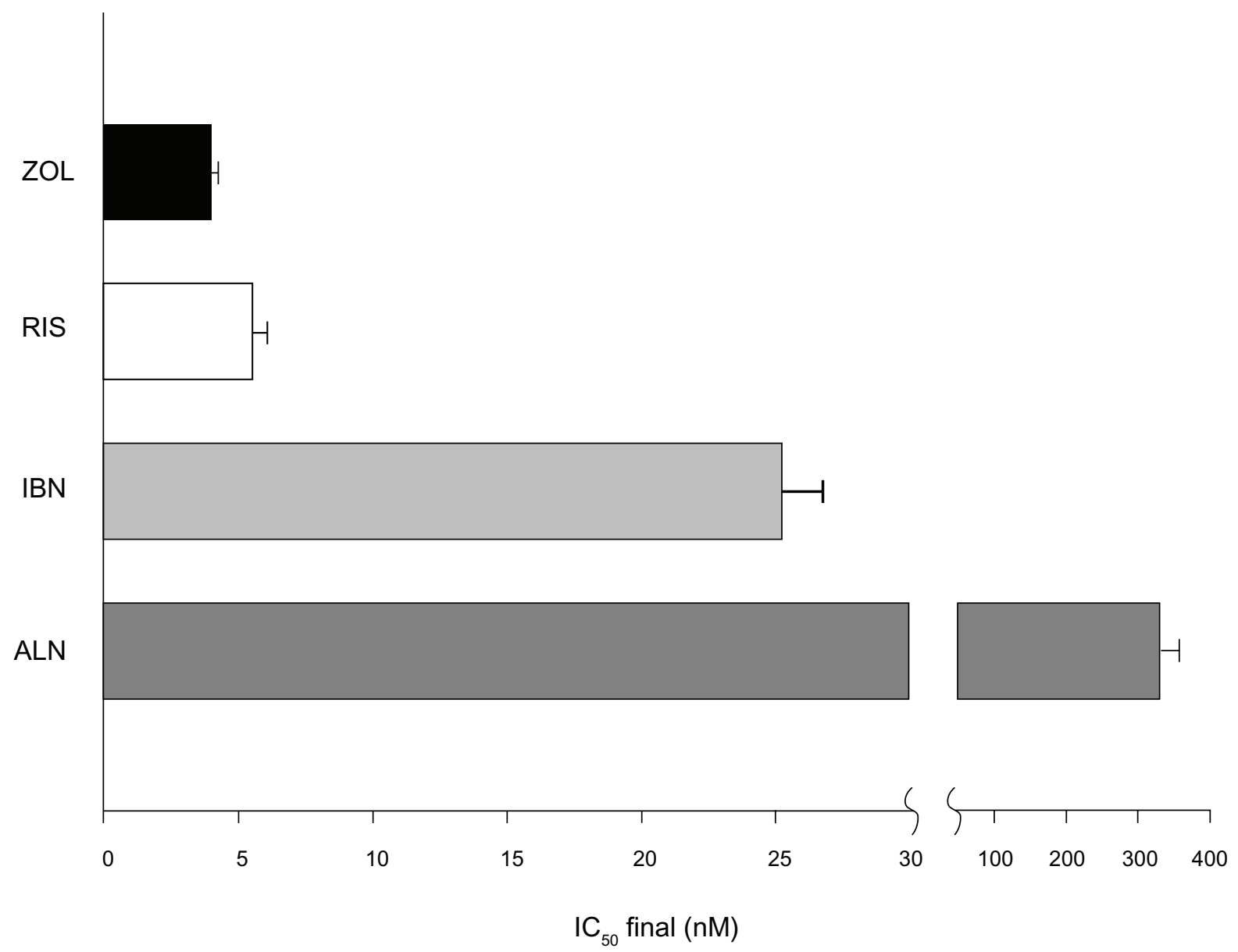

Figure 2 Farnesyl pyrophosphate synthase enzyme inhibition potency $\left(\mathrm{IC}_{50}\right)$ of nitrogen-containing bisphosphonates (inhibition of $50 \%$ of maximum enzyme activity). Note that zoledronic acid shows the higher affinity for the mineral matrix combined with the higher inhibition potency of farnesyl pyrophosphate synthase. ${ }^{26}$ Abbreviations: ALN, alendronate; IBN, ibandronate; RIS, risendronate; ZOL, zolendronic acid.

Oral administration comes with specific instructions to optimize the adsorption and to avoid possible esophageal lesions. The dose must be taken on an empty stomach, with abundant water intake at least 30-45 minutes before eating, and while sitting or standing up. It has been estimated that at least $50 \%$ of patients taking oral BPs discontinue the therapy within 1 year, ${ }^{26}$ and many patients do not take their drugs according to the instructions described above. ${ }^{49-52}$

Post-marketing studies indicate that $20 \%-30 \%$ of patients treated with alendronate or risedronate discontinue the drug, mainly because of side effects. ${ }^{49,50}$ This is clinically relevant because poor compliance compromises treatment efficacy, and increases fracture incidence and medical costs. ${ }^{7,49}$

\section{Upper gastrointestinal intolerance}

GI intolerance, in particular in the upper GI tract (nausea, vomiting, epigastric pain, and dyspepsia), is often associated with the use of oral BPs. ${ }^{53}$ Esophagitis is the most important and frequent side effect, and its incidence was more or less similar in a head-to-head comparison between alendronate and risedronate ${ }^{54}$ Endoscopic examination showed that esophagitis was caused by direct contact between the tablet and the mucosa. Prolonged contact of the tablet with the esophageal mucosa can induce local irritation; this problem can be prevented by strict adherence to the above-mentioned dosing instructions.

Esophagitis was common with daily formulations but the incidence has decreased significantly after the introduction of weekly and monthly BP administration. ${ }^{55}$ Intravenous formulations of zoledronate and ibandronate avoid this problem.

\section{Acute phase reaction}

Acute phase reaction encompasses a variety of symptoms generally described as fever, myalgia, fatigue, chills, and arthralgia. It is common with all NBPs, whether administered orally or intravenously, but is certainly more frequent and intense with the more potent intravenous formulations. ${ }^{12}$ Symptoms are typically transitory, resolving within 3 days of onset and reduced by commonly used anti-inflammatory and antipyretic agents. ${ }^{8}$ 
The symptoms are particularly common with zoledronic acid, and include pyrexia (16.1\%), myalgia (9.5\%), flu-like symptoms (7.8\%), headache (7.1\%), and arthralgia (6.3\%). All these events decreased dramatically with subsequent infusions. Symptoms were reported in $30 \%$ of patients after the first infusion, in $6.6 \%$ after the second, and $2.8 \%$ after the third. ${ }^{8}$ The mechanism responsible for these effects is linked both to the direct stimulation of $\gamma / \delta$ lymphocytes and to the intracellular accumulation of isopentenyl pyrophosphate due to the inhibition of farnesyl diphosphate synthase. ${ }^{56}$

Although it is usually reported as a side effect, the stimulation of a subgroup of $\gamma / \delta$ T-lymphocytes could be responsible for the indirect antineoplastic activity of zoledronic acid. ${ }^{57}$

An interesting association between acute phase reaction and vitamin D deficiency has recently been demonstrated, indicating that adequate supplementation with vitamin D before the infusion contributes to reduce the incidence of symptoms..$^{58}$

\section{Renal safety}

BPs are excreted by the urinary system and can induce impairment of renal function. The mechanism of the damage is the same as that responsible for the therapeutic effect, ie, blockage of the mevalonate pathway, with apoptosis of tubular cells. ${ }^{59}$ Because renal damage is closely correlated with the concentration/time ratio of drugs in the kidney, intravenous formulations potentially carry a higher risk of renal impairment.

The renal safety of zoledronic acid has been monitored in the Pivotal Fracture Trial (PFT). No signs of significant renal dysfunction were reported following 3 years of intravenous treatment with zoledronic acid in patients with a baseline creatinine clearance $\geq 30 \mathrm{~mL} / \mathrm{min}$. In 31 patients treated with zoledronic acid, a transient elevation of creatinine levels has been observed, which normalized completely within one month in 27 patients and in all patients by one year. Assessments at 12,24, and 36 months showed no significant differences between groups in serum creatinine or creatinine clearance change from baseline. ${ }^{8,60}$ Moreover, the reduction of creatinine clearance in patients with mild to moderate renal dysfunction was not different from that in the placebo group.

The safety of zoledronic acid has been also tested in MBD where the dosage and rate of infusion are much higher than for PO. These patients are usually at high risk of renal dysfunction from pre-existing renal disease, concomitant treatments, frequent use of non-steroidal anti-inflammatory drugs, and hypercalcemia, but data from a meta-analysis indicate that zoledronic acid infusion is generally safe. ${ }^{61}$ Nevertheless, the duration of infusion is important because a period shorter than 15 minutes, achieving high drug concentrations in the renal tubule, could damage tubular cells. This problem can be avoided with an infusion exceeding 15 minutes. ${ }^{62}$ Moreover, because clinical studies indicate that there is no evidence of excessive drug accumulation secondary to renal failure, no adjustment of the dosage is necessary in patients with PO and nephropathy. ${ }^{62}$

At present, the summary of product characteristics recommends caution when using zoledronic acid in patients with a creatinine clearance $<30 \mathrm{~mL} / \mathrm{min}$, not because of established risk of toxicity, but on the basis of the limited data available. ${ }^{63}$

\section{Cardiovascular safety}

Atrial fibrillation (AF) is the only relevant cardiac side effect reported in patients treated with BPs. AF occurred in the PFT in 50 patients $(1.3 \%)$ treated with zoledronic acid and in 20 patients $(0.6 \%)$ treated with placebo $(P<0.001) .{ }^{8}$ Notably, 47 of 50 cases of AF were recorded more than 30 days after zoledronic acid infusion, when the drug was no longer detectable in serum. Furthermore, an electrocardiogram substudy, conducted in 559 patients before study initiation and 9 to 11 days after the third infusion, failed to reveal any cardiac arrhythmias of note. Other cardiovascular adverse events, eg, stroke and myocardial infarction, did not show any significant difference between groups, nor was there a significant difference in the overall incidence of death from cardiovascular causes. A retrospective analysis of the Fracture Intervention Trial (FIT) highlighted a trend toward a higher incidence of AF in patients treated with alendronate, similar to that observed with zoledronic acid. In this study, 47 patients $(1.5 \%)$ treated with alendronate and $31(1 \%)$ of those in the placebo group developed $\mathrm{AF}^{64}$

No studies are available to suggest a biologic mechanism for a relationship between BPs and development of AF. Alterations of serum calcium, changes in intracellular ion concentrations, QT prolongation, and/or production of specific proinflammatory, profibrotic, and antiangiogenic cytokines have been suggested, but no significant treatment-related changes in these parameters have been observed thus far. ${ }^{65-67}$ At present, this problem seems not to be clinically relevant, but more extensive and specific studies should be carried out to clarify the relationship between AF and BP treatment.

\section{Hypocalcemia}

BPs are potent inhibitors of osteoclast activity and could trigger an acute decrease of serum calcium and phosphorus 
concentrations associated with a secondary parathyroid hormone (PTH) increase. ${ }^{68} \mathrm{PTH}$ maintains the serum calcium level by increasing renal tubular reabsorption and synthesis of 1,25-dihydroxyvitamin D, and indirectly stimulates osteoclasts via osteoblasts. Symptomatic hypocalcemia is uncommon with oral bisphosphonates, ${ }^{69}$ but the more potent intravenous formulations may cause symptomatic hypocalcemia within a few days postinfusion, overcoming the PTH effect. ${ }^{70}$ Risk factors for hypocalcemia include the presence of hypoparathyroidism, vitamin D deficiency, and renal failure.

In the Health Outcomes and Reduced Incidence with Zoledronic Acid Once Yearly (HORIZON)-PFT study, 2.3\% of patients in the zoledronic acid group showed hypocalcemia, defined as serum calcium levels $<2.075 \mathrm{mmol} / \mathrm{L}$, 9-11 days after the first infusion. All cases were transient and asymptomatic. ${ }^{8}$ In clinical practice, appropriate calcium and vitamin D supplementation prevents hypocalcemia, and correction of vitamin D deficiency is also recommended. ${ }^{71}$

\section{Ocular adverse events}

Nonspecific conjunctivitis is the most common ocular side effect of the BPs. ${ }^{72,73}$ This is usually transient and improves without specific therapy or discontinuation of BP therapy. Other ocular side effects, such as eye lid edema, optic or retrobulbar neuritis, periorbital edema, cranial nerve palsy, and ptosis have been reported. The most frequent cranial nerve side effect is optic nerve neuritis, but the release of cytokines after bisphosphonates administration might provoke also extraocular muscle inflammation and involve orbital motility. ${ }^{74}$

Uveitis and scleritis are the most serious ocular complications of BP therapy, and require discontinuation of treatment. However, the true incidence of these side effects is unknown. ${ }^{72,73}$

A large cohort study determined the six-month incidence of uveitis/scleritis during BP treatment. The relative risk of uveitis/scleritis over 6 months was 1.23 (95\% confidence interval [CI] 0.85-1.79) compared with patients not treated with BPs. There was no significant difference in the incidence of uveitis/scleritis between BP users and nonusers, nor between oral or intravenous bisphosphonate administration. ${ }^{73}$

An association with concomitant systemic diseases (such as ankylosing spondylitis, Behçet syndrome, psoriasis, Reiter syndrome, inflammatory bowel diseases, polychondritis, Wegener's granulomatosis, rheumatoid arthritis, systemic lupus erythymatosus, sarcoidosis, and syphilis) or treatments (rifabutin, trimethoprim-sulfamethoxazole, diethylcarbamazine, metipranolol, and cidofovir) have been reported, and it has been postulated that in these situations BPs could act as a precipitating factor. ${ }^{73}$ Vigilance is therefore necessary when BPs need to be administered in patients with these diseases or receiving these concomitant therapies.

\section{Atypical femoral diaphysis fractures}

In the last few years, a new association between long-term BP treatment and unusual, low-energy, nonvertebral fractures has been reported. ${ }^{75}$ Until now, this complication was reported only in patients taking oral BPs, in particular alendronate. ${ }^{76}$

Bone biopsies in these patients show evidence of severely suppressed bone turnover, considered to be the cause of adynamic bone disease, which presumably accounts for increased bone fragility resulting in atypical fractures. ${ }^{75}$ The radiographic pattern is distinctive, and defined as a simple transverse or oblique $\left(\leq 30^{\circ}\right)$ fracture, with breaking of the cortex and diffuse cortical thickening of the proximal femoral shaft. ${ }^{77}$

The majority of the relevant studies have concerned alendronate because this is the most widely used BP. The effect is probably common to all BPs, but, at the moment, there are no findings available for the other agents. Nevertheless, femoral shaft fractures are rare in BP users, indicating that the pathogenesis is complex and probably not directly related to BP treatment, and probably more related to patient characteristics. A genetic susceptibility of osteoclasts to BP-induced oversuppression has been postulated, ${ }^{78}$ as well as the presence of one or more predisposing factors, such as diabetes mellitus, chronic corticosteroid treatment for pulmonary diseases, rheumatoid arthritis, and severe osteoarthritis, ${ }^{79}$ or the existence of femur cortical hypertrophy, that is often present before the beginning of treatment. ${ }^{79}$ The question of whether low-energy subtrochanteric or proximal femoral shaft fractures are more frequent in alendronate (or any other BP) users compared with nonusers cannot be answered at present.

Patients treated with the more widely used BPs should be informed that persistent and increasing pain in the region of the upper part of the femur may be prodromal of a proximal diaphysis fracture, and a radiologic evaluation should be performed.

\section{Osteonecrosis of the jaw}

Osteonecrosis of the jaw (ONJ) developing during BP treatment is a form of chronic osteomyelitis, involving mainly the jaw and maxilla, and attributable to pathogens usually present in the mucosa of the mouth, such as Actinomyces israeli. ${ }^{80}$ In addition to BP use, other risk factors have been identified, including coexisting solid tumors or multiple myeloma 
treated by chemotherapy, and other conditions associated with immunosuppression, such as diabetes mellitus and corticosteroid treatment. A dental procedure is often the precipitating factor, especially if associated with bad dental hygiene and inadequate antibiotic propylaxis. ${ }^{80}$ The incidence is very low, ie, less than 1/100,000 in PO patients treated with BPs in Germany $^{81}$ and $0.01 \%-0.04 \%$ in Australia. ${ }^{82}$ In the HORIZON study, no cases of ONJ were observed in 7000 patients, and a retrospective analysis showed two cases of ONJ, one in the treated group and one in the placebo group. ${ }^{83}$

Many authors have suggested that the pathogenesis of ONJ is directly linked to osteonecrosis of bone due to excessive suppression of bone turnover. ${ }^{47}$ In contrast, histologic analyses showed that ONJ is a typical osteomyelitis characterized by a high cellular infiltrate, and an intense osteoclast and osteoblast reaction indicating that bone turnover is not oversuppressed by the therapy. ${ }^{48}$ Oversuppression of bone turnover after bisphosphonates has been discounted by bone biopsy analyses in osteoporotic patients treated with zoledronic acid. ${ }^{84}$

The cumulative BP dose has been proposed as one of the most important risk factors for the development of ONJ, ${ }^{85}$ but the wide range of doses found to have been administered at the onset of ONJ suggests that this is unlikely. Recently, it has been proposed that soft tissue toxicity from BPs might be involved in the pathogenesis of ONJ. ${ }^{86}$ Moreover, the majority of cases of ONJ reported up until now have been described in patients taking BPs for bone metastases, in which higher doses are used.

Consequently, it can be concluded that, nowadays, the role of BPs in the development of ONJ is still uncertain and a matter of debate, given that BPs are probably only one of many treatment-related factors. At the moment, there are some guidelines and general recommendations to prevent ONJ, but are not widely accepted. ${ }^{87,88}$ It seems useful to maintain adequate oral hygiene and use antibiotic prophylaxis in the event of a dental procedure, but suspension of BP treatment would seem unhelpful, given the long duration of drug persistence in bone.

\section{Efficacy}

Alendronate, risedronate, ibandronate, and zoledronate are approved for the treatment of osteoporosis (Table 1). All these molecules demonstrate a significant reduction of fracture risk (Figure 3).

Alendronate is available in both daily $(10 \mathrm{mg})$ and weekly (70 mg) formulations. It has been shown to increase BMD significantly at all skeletal sites, and after 3 years the increment at the lumbar spine was about $8 \%$, while the reduction of fracture risk was $47 \%$ for vertebral and $40 \%-50 \%$ for nonvertebral fractures. ${ }^{89}$ Prolonged treatment (data available for up to 10 years) has demonstrated the persistent efficacy of alendronate, characterized by a continuous increase in BMD and a reduction of new vertebral fractures. ${ }^{1}$ Discontinuation of alendronate is characterized by a long inhibition of bone turnover that guarantees the persistence of pharmacologic effects of the drug that are strictly dependent on the duration of treatment.

Recently, a new weekly formulation of alendronate supplemented with two different dosages of cholecalciferol (2800 IU and 5600 IU) has been approved. The once-weekly alendronate-vitamin $\mathrm{D}$ tablet was shown to increase patient compliance, to provide an antiresorptive efficacy equivalent to once-weekly alendronate $70 \mathrm{mg}$ without cholecalciferol, and to improve vitamin D status. It was not associated with hypercalcemia, hypercalciuria, or other adverse effects..$^{90,91}$

Risedronate is marketed in three formulations, ie, $5 \mathrm{mg}$ daily, $35 \mathrm{mg}$ weekly, and $150 \mathrm{mg}$ monthly $(75 \mathrm{mg}$ on 2 consecutive days in Europe).$^{92}$ Like alendronate, risedronate significantly increases BMD by approximately $6 \%$ at the lumbar spine after 3 years of treatment (Table 1). Fracture risk reduction was significant at both the vertebral $(-49 \%)$ and femoral sites $(-40 \%) .^{93}$

Risedronate is characterized by a rapid onset of antifracture effect that becomes significant within 6 months of starting treatment. Prolonged treatment (7-year data available) demonstrated the persistence of a risedronate effect on BMD increase and fracture prevention. ${ }^{43}$ However, after discontinuation, bone turnover comes back rapidly towards the pretreatment level, although fracture risk reduction is maintained for more than 1 year. $^{44}$

Risedronate and alendronate are usually prescribed for the treatment of PO, but they are also approved for glucocorticoid-induced osteoporosis (GIO) and for male osteoporosis..$^{94-97}$

Ibandronate is available in both oral (150 mg monthly) and intravenous ( $3 \mathrm{mg}$ every 3 months) formulation. It has been registered for osteoporosis on the basis of studies using a daily dosage of $2.5 \mathrm{mg}$ which showed a significant vertebral fracture risk reduction $(62 \%$ with the daily and $50 \%$ with the intermittent formulation after 3 years versus placebo), while the reduction of nonvertebral fractures was evident only in a post hoc analysis in a higher-risk subgroup of patients (femoral T score $<-3$ ). ${ }^{42,98,99}$ Nevertheless, it is now marketed at an oral dosage of $150 \mathrm{mg}$ monthly or $3 \mathrm{mg}$ intravenously every 3 months. 
Table I Bisphosphonates approved for the treatment of osteoporosis

\begin{tabular}{|c|c|c|c|c|}
\hline Bisphosphonate & Dosage & Administration & Indications & $\begin{array}{l}\text { Lumbar spine } \\
\text { BMD increase }\end{array}$ \\
\hline \multirow[t]{3}{*}{ Alendronate } & 10 mg (daily) & Oral & Postmenopausal & $+8 \%{ }^{64}$ \\
\hline & 70 mg (weekly) & & glucocorticoid & $+2.9 \%^{94}$ \\
\hline & & & male & $+5.3 \%{ }^{96}$ \\
\hline \multirow[t]{3}{*}{ Risedronate } & 5 mg (daily) & Oral & Postmenopausal & $+6 \%^{93}$ \\
\hline & 35 mg (weekly) & & glucocorticoid & $+2.7 \%{ }^{95}$ \\
\hline & 150 mg (monthly) & & male & $+4.6 \%{ }^{97}$ \\
\hline \multirow[t]{2}{*}{ lbandronate } & 150 mg (monthly) & Oral & Postmenopausal & $+5 \%^{98}$ \\
\hline & $3 \mathrm{mg}$ (quarterly) & intravenous & & $+6.5 \%{ }^{99}$ \\
\hline \multirow[t]{2}{*}{ Zoledronate } & 5 mg (yearly) & Intravenous & Postmenopausal & $+6.7 \%^{8}$ \\
\hline & & & male & $+6.3 \%^{102}$ \\
\hline
\end{tabular}

\section{Zoledronic acid}

The first dose-finding trial was of 1 year's duration, and included 351 postmenopausal women with a lumbar spine BMD T score $\leq-2.0 .{ }^{9}$ Patients were randomized to receive placebo or intravenous zoledronic acid at doses of $0.25 \mathrm{mg}$, $0.5 \mathrm{mg}$, or $1 \mathrm{mg}$ every 3 months, $2 \mathrm{mg}$ every 6 months, or a single dose of $4 \mathrm{mg}$.

All patients treated with zoledronic acid showed a significant increase in lumbar BMD (mean values 4.3\%-5.1\% higher than for placebo) and in femoral neck BMD (mean values 3.1\%-3.5\% higher than for placebo) at the end of the 1 -year study. Markers of bone resorption and formation were also significantly decreased in comparison with placebo at all time points (months 3, 6, and 12). To assess bone quality, a subset of patients underwent transiliac bone biopsy after tetracycline double-labeling and these analyses showed normal bone structure in patients treated with zoledronate, with no evidence of histologic alterations, osteomalacia, or signs of bone turnover below the limit of the premenopausal range. ${ }^{9}$

To generate more data on long-term treatment, all patients were allowed to extend their treatment for additional 2 years. ${ }^{100}$ Lumbar spine BMD increased at 5 years from a mean of $6.4 \%$ to $9.0 \%$ and from $4.9 \%$ to $5.5 \%$ at the proximal femur. Levels of the resorption serum marker, Type I collagen C-telopeptide $(\beta-\mathrm{CTx})$, were consistently reduced to around the standard premenopausal range during the observation period. Bone resorption markers remained within the premenopausal reference range during long-term treatment, but there was a clear trend of increasing values after the evaluation period. After 5 years of treatment, b-ALP decreased by a mean of $36.6 \%$, while in the 1-year core study b-ALP reduction reached its nadir at 6 months, with an upward trend in the second half of the study period. At the end of the core study, about $37 \%$ of patients did not reach a $30 \%$ reduction in b-ALP levels, ${ }^{100}$ which is considered the cutoff for achieving a clinical benefit with regard to nonvertebral fractures. ${ }^{101}$

On the basis of these results, the HORIZON study was planned. This 3-year, international, randomized, doubleblind, placebo-controlled trial was designed to demonstrate the efficacy of zoledronic acid $5 \mathrm{mg}$ once yearly in reducing fractures at all prevalent bone sites. ${ }^{8}$ The patients enrolled were osteoporotic women aged between 65 and 89 years with a BMD T score $\leq-2.5$ at the femoral neck or a $\mathrm{T}$ score of $\leq-1.5$, and with radiologic evidence of at least two mild vertebral fractures or one moderate vertebral fracture. The patients were randomly assigned to receive either one infusion of zoledronic acid or placebo once a year for 3 years. All subjects also received daily oral calcium (1000-1500 mg) and vitamin D (400-1200 IU) supplementation.

At 36 months, zoledronic acid significantly reduced the risk of new morphometric vertebral fractures by $70 \%$, hip fractures by $41 \%$, and nonvertebral fractures by $25 \% .{ }^{6} \mathrm{~A}$ significant increase of BMD at all skeletal sites was consistently observed, in particular, $+6.02 \%$ at the total hip, $+5.06 \%$ at the femoral neck, and $+6.71 \%$ at the lumbar spine. Markers of bone formation (b-ALP and N-terminal propeptide of Type I collagen), and resorption ( $\beta$-CTx) showed a rapid and stable trend toward the standard premenopausal reference range. ${ }^{8}$

The HORIZON investigators also evaluated zoledronic acid as a secondary prevention strategy for osteoporotic fractures. They randomized 2127 subjects within 90 days of hip fracture surgery to receive intravenous zoledronic acid $5 \mathrm{mg}$ or placebo on a yearly basis. At 36 months, the treated group showed significantly increased BMD at the total hip and femoral neck compared with the placebo group. Over a 1.9-year median follow-up, the investigators observed a significant decrease in any new fracture (absolute risk reduction [ARR] 5.3\%), clinical vertebral fractures (ARR $2.1 \%$ ), nonvertebral fractures (ARR 3.1\%), and recurrent 


\section{A}

$\mathrm{Fx} \%$

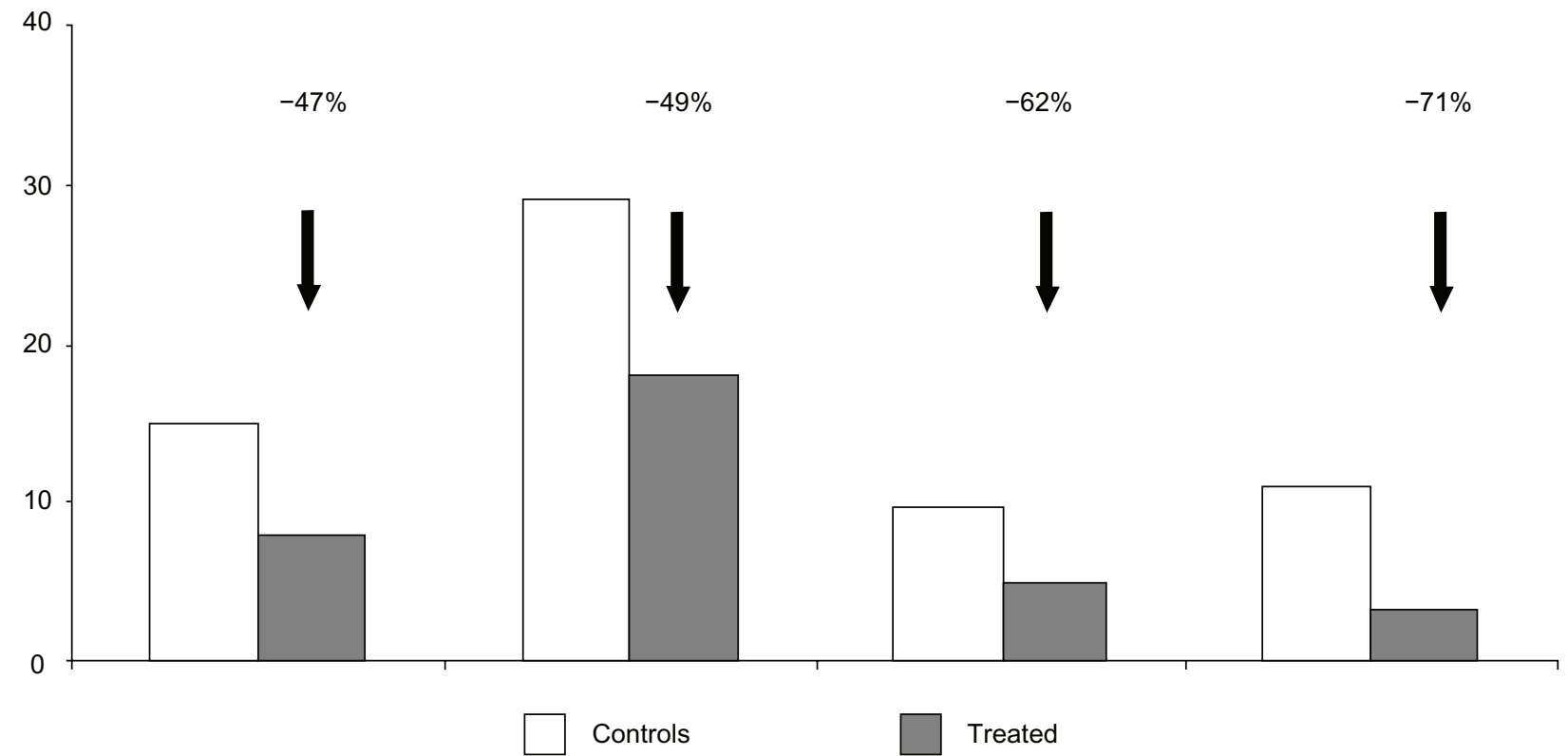

B

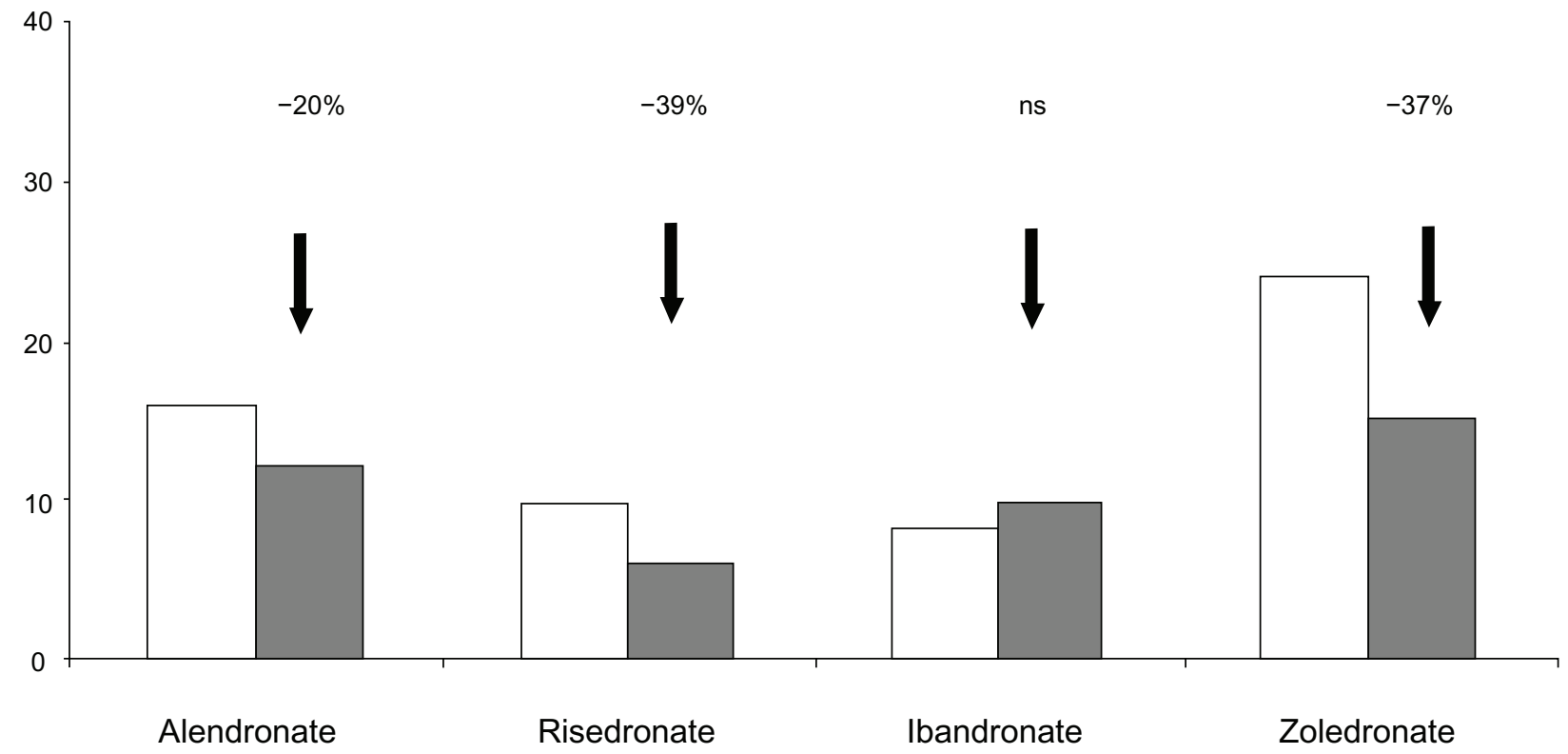

Figure 3 Reduction of new vertebral A) and femoral B) fractures after treatment with several common bisphosphonates.

hip fractures (ARR 1.5\%). In this population at high risk for recurrent and potentially fatal fractures, the zoledronic acidtreated group also experienced a survival advantage (relative risk reduction [RRR] 28\%, ARR 3.7\%). ${ }^{102}$ This was the first study highlighting a reduction in mortality after treatment with bisphosphonates.

Within the efficacy data for the bisphosphonates, some evidence has emerged supporting the possibility of switching between different formulations. For example, in a one-year, randomized, active-controlled trial, the safety of switching from alendronate to zoledronic acid was evaluated in postmenopausal women with low BMD. ${ }^{103}$ Patients enrolled in this study had lumbar spine or femoral neck BMD $\mathrm{T}$ scores $\leq-2.0$. All patients were treated with alendronate for at least one year (average 4 years). Subjects were randomized to either a 15-minute intravenous infusion of zoledronic acid $5 \mathrm{mg}$ plus 52 weeks of oral placebo or to an infusion of placebo plus 52 weeks of weekly oral alendronate $70 \mathrm{mg}$. 
The lumbar spine BMD increase compared with baseline was similar for the two groups. Bone resorption markers measured were Type I collagen N-telopeptide corrected for creatinine and serum $\beta$-CTx, while the bone formation markers measured were serum $\mathrm{b}$-ALP and N-terminal propeptide of Type I collagen). In the alendronate group, the urinary and serum biomarkers of bone resorption remained close to baseline values. In contrast, biomarkers were significantly reduced in the zoledronate-treated group after 3 months $(P<0.05)$, returned to baseline after 6 months, and significantly increased compared with baseline $(P<0.05)$ at the end of the study, but were still within the premenopausal reference range.

No signs of abnormalities in bone structure were revealed in biopsies obtained in a subgroup of patients. The safety profile was similar between the treatments, with the exception of the expected higher incidence of acute phase flu-like syndrome in the group treated wth zoledronic acid $(36.3 \%$ versus $21.4 \%$ ).

\section{Zoledronic acid and glucocorticoid- induced osteoporosis}

As mentioned earlier, alendronate and risedronate are approved for GIO. More recently, zoledronate has also been registered for this indication. The efficacy and safety of onceyearly intravenous zoledronic acid $5 \mathrm{mg}$ in GIO has been evaluated in a one-year randomized, multicenter, doubleblind, stratified study using daily oral risedronate as the active control. This study was conducted in 833 men and women aged 18-85 years. The study prerequisite was treatment with $>7.5 \mathrm{mg} /$ day or equivalent of oral prednisone. ${ }^{104}$

Patients were stratified according to the duration of glucocorticoid treatment prior to their inclusion in the study, ie, less than 3 months (prevention arm) or more than three months (treatment arm). Adequate calcium supplementation of $1000 \mathrm{mg} /$ day was given to all patients, as well as cholecalciferol 400-1000 IU/day. After 1 year of treatment, zoledronate-treated patients showed a significantly greater increase of lumbar spine BMD compared with those on oral risedronate $(4.06 \%$ versus $2.71 \%$, respectively, $P=0.0001$ ) and of femoral neck BMD (1.45\% versus 0.39 , respectively, $P=0.005)$. Similar results were observed in the prevention group. Zoledronic acid showed a faster and more persistent inhibitory effect on bone resorption markers than risedronate (Figure 4). In contrast, the inhibition of bone formation markers was higher in the risedronate-treated group. This effect could represent an advantage in this particular setting, in which the reduction of BMD with an associated increased risk of fracture occurs within a few months after starting glucocorticoid treatment. ${ }^{105}$

\section{Zoledronic acid and male osteoporosis}

Twenty percent of men older than 60 years will experience a fracture, but age-related bone loss in men is still underrecognized and undertreated. ${ }^{106}$ Hip fractures increase the mortality risk by 4 -fold in the first 3 months after a fracture, and 1 -year mortality reaches $20 \% .{ }^{107}$ Alendronate and risedronate are approved for the treatment of osteoporosis in men. These BPs have been shown to induce a significant increase of lumbar spine and femoral BMD, as well as a reduction in vertebral fractures, but there are still limited data available for nonvertebral fractures..$^{96,97}$

The HORIZON investigators evaluated zoledronic acid in the secondary prevention of osteoporotic fractures and, of the 2127 subjects recruited, $24 \%$ were men. ${ }^{102}$ Within 90 days of surgical repair of a hip fracture, participants received $5 \mathrm{mg}$ of intravenous zoledronic acid or placebo. At 36 months, they had significantly increased BMD at the total hip and femoral neck compared with the placebo group and a significant decrease in any new fracture. As already mentioned, the treated population had a survival advantage (RRR 28\%, ARR 3.7\%) that was greater in men than in women (overall mortality ARR 6.4\%) and, interestingly, a marked reduction in cardiac-related deaths (RRR $62.0 \%$ and RRR 4.8\%, respectively). ${ }^{102}$ These data are interesting, although further confirmations are needed.

\section{Zoledronic acid and hormone suppressive therapy \\ Aromatase inhibitors and osteoporosis}

Aromatase inhibitors result in a longer disease-free survival interval and produce fewer endometrial and thromboembolic adverse events (AEs) than tamoxifen. ${ }^{108}$ Consequently, more women are receiving aromatase inhibitors as first-line adjuvant hormonal therapy or following tamoxifen therapy. However, aromatase inhibitors inhibit almost completely the production of endogenous estrogens that are necessary for bone health, ${ }^{109}$ and women treated with these agents have a rapid reduction of $\mathrm{BMD}$ associated with a rapid increase of bone turnover and a high risk of fractures. ${ }^{110}$ Zoledronic acid has been studied for the prevention and treatment of bone loss and for the reduction of risk fracture in this population.

The two most important studies performed, Z-FAST and Zo-FAST, showed that early-stage breast cancer patients who received zoledronic acid ( $4 \mathrm{mg}$ intravenously every 6 months) had better preserved bone mass during the first 12 months of 

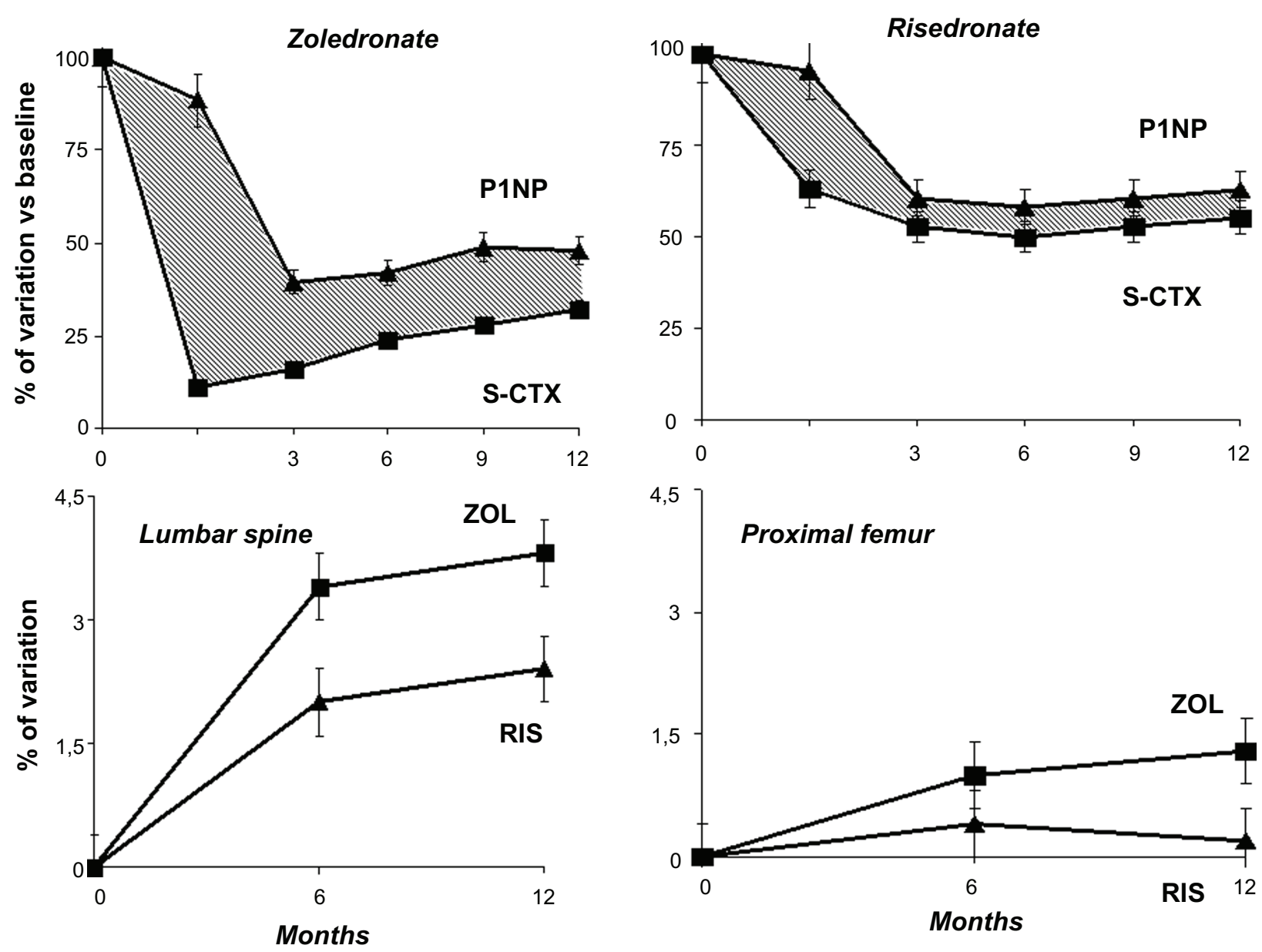

Figure 4 Effects on bone density and turnover between zoledronate and risedronate in glucocorticoid-induced osteoporosis. Note that zoledronate induces a rapid and higher suppression of resorption markers with respect to risedronate. This can explain the higher increase of bone density with zoledronate in this particular setting.

aromatase inhibitor therapy compared with patients allocated to delayed administration of zoledronic acid $(P<0.001$ at both BMD sites in both studies). ${ }^{110-112}$ The positive effect of zoledronic acid on BMD is consistent with the rapid and sustained decrease of serum collagen Type 1 N-telopeptide and b-ALP during the first 12 months of adjuvant letrozole therapy. In light of these findings, clinicians prescribing aromatase inhibitors should consider a fracture risk assessment and effective treatment to prevent bone loss and fractures.

\section{Androgen inhibitors and osteoporosis}

Prostate cancer is a common disease in men, and androgen deprivation therapy (ADT) is associated with a risk of osteoporosis and fractures. Zoledronic acid has been tested successfully in this setting. ${ }^{113}$ Two studies evaluated zoledronate $4 \mathrm{mg}$ intravenously every 3 months in men with nonmetastatic prostate cancer and embarking on ADT. At 1 year, BMD at the lumbar spine, femoral neck, and total hip decreased $2 \%-3 \%$ in the placebo group, while the treated group showed significant increases at the same skeletal sites
(6.7\%-7.8\% at the lumbar spine, $3.3 \%-3.6 \%$ at the femoral neck, and $3.8 \%-3.9 \%$ at the total hip). ${ }^{113-115}$

\section{Other applications}

\section{HIV-related bone loss}

Human immunodeficiency virus (HIV) infection and highlyactive antiretroviral therapy are associated with low BMD and osteoporosis. Brown et al found that the prevalence of osteoporosis in HIV-infected individuals is more than three times greater compared with HIV-noninfected controls. ${ }^{116}$ An annual infusion of $4 \mathrm{mg}$ of zoledronate in HIV-infected men with decreased BMD receiving antiretroviral therapy achieved a significant decrease in bone turnover markers (urinary collagen Type $1 \mathrm{~N}$-telopeptide $-61 \%$ and serum total ALP - 21\%) by 3 months and a significant increase of lumbar spine (4.6\%) and total hip (6.3\%) compared with the control group. ${ }^{117}$

\section{Transplant-related bone disease}

Osteoporosis is an increasingly frequent complication of end-stage organ failure, and bone loss and fracture risk is 
particularly high both before and after organ transplantation. Research has demonstrated the efficacy of oral bisphosphonates $^{118,119}$ as well as of an intravenous formulation of zoledronic acid ${ }^{120}$ in transplant patients. In particular, a study by Crawford et al in liver transplantation demonstrated that zoledronic acid had a positive effect on bone density that was independent of the glucocorticoid dose being administered. Bone loss was significant at the femoral level, while bone density was maintained in the group treated with zoledronic acid, in whom a higher degree of bone turnover suppression was also observed. ${ }^{120}$

Previous studies on osteoporosis therapies in transplanted recipients showed inconsistent and unconvincing findings, but the data for zoledronate suggest that a more potent bisphosphonate administered as soon as is feasible after surgery and at more frequent intervals can prevent bone loss after transplantation. The use of zoledronate in this population appeared to be safe, in particular there was no reported impairment of renal function. ${ }^{120}$

\section{Prevention of postmenopausal osteoporosis}

Zoledronic acid has been recently investigated for the prevention of PO in a 2-year, randomized, multicenter, doubleblind, controlled trial study of 1140 osteopenic women who were assigned to receive two infusions of zoledronic acid $5 \mathrm{mg}$ (one per year), only one infusion of $5 \mathrm{mg}$, or placebo. ${ }^{46}$

After 2 years, spine BMD was increased by $5.18 \%$ in women who received the twice-yearly zoledronic acid infusion and by $4.18 \%$ in those who received a once-yearly zoledronic acid infusion, compared with a $-1.32 \%$ decrease in the placebo group. A significant BMD increase was also observed at the proximal femur. In particular, total hip BMD increased by $2.91 \%$ with the twice-yearly zoledronic acid infusion, by $2.28 \%$ with the once-yearly zoledronic acid infusion, compared with $-1.45 \%$ in the placebo group.

The reduction in bone turnover markers showed a similar pattern from baseline to 12 months. At month 12, bone turnover decreased significantly in the twice-yearly zoledronic acid infusion group after the second infusion, but slightly increased during the second year in the once-yearly zoledronic acid infusion group.

The results of this study suggest that zoledronic acid could also be effective for the prevention of bone loss in osteopenic postmenopausal women. Although information on fractures is not yet available, these data are of interest because they suggest that the use of zoledronic acid is beneficial in patients with a moderate fracture risk or with pathologic conditions associated with bone loss in which BPs have not been yet extensively studied (eg, in transient immobilization, anorexia, early menopause, and conditions associated with high bone turnover, including hyperparathyroidism and hyperthyroidism).

\section{Patient considerations}

Patients are strictly monitored and compliance and persistence are generally high in controlled clinical trials, but it is difficult to monitor compliance in everyday clinical practice because compliance data are usually collected from patient self-reporting, which may be inaccurate. It has been reported that compliance for patients treated with oral bisphosphonates is poor after 12 months, and compliance rates decrease steadily over time. ${ }^{49,50,121}$

There is good evidence demonstrating that compliance over one year is better with weekly administration than with daily dosing, ${ }^{122}$ and even better persistence is achieved with the monthly formulations of ibandronate. ${ }^{123}$

Poor compliance with oral formulations can explain the difference between rates of BMD increase and fracture incidence seen in clinical trials and in daily clinical practice. ${ }^{49,50,121}$ There are many reasons explaining low persistence and poor compliance, ie, lack of immediate benefits that can be recognized by patients, real or perceived adverse effects, costs, and an inconvenient oral dosing regimen, the latter being the major cause for noncompliance, as previously discussed. Adherence with alendronate is significantly better with the weekly oral formulation than with the daily one. From another point of view, once-weekly or monthly dosing may be harder to remember than daily dosing. ${ }^{121}$

The possibility of once-yearly intravenous BP administration provides the opportunity to increase patient compliance, which will optimize clinical, densitometric, and antifracture outcomes. In the case of once-yearly zoledronic acid, compliance is $100 \%$ during the first year of follow-up not only in trials but also in clinical practice. As a consequence, the reduction of fracture rate in real life would be expected to be similar to that observed in the clinical trials. ${ }^{8,121}$

At present, there are still no studies focused on patient satisfaction and preference, although some data can be extrapolated from the larger clinical trials. In general, as expected, yearly intravenous BP administration was preferred over weekly oral administration, ${ }^{45,103}$ despite some authors reporting $20 \%$ of patients having a preference for weekly oral therapy, and $14 \%$ having no preference for either option. ${ }^{124}$ The data available indicate that intravenous BP administration is generally well tolerated and preferred instead to oral 
formulations, the latter often being more commonly used in daily clinical practice, because of their ready availability for general practitioners.

\section{Conclusion}

BPs have modified the prognosis for patients with osteoporosis. They reduce the incidence of fragility fractures significantly, and improve quality of life for patients with bone disease. The different molecules and formulations available allow modulation of treatment in the individual patient, increasing compliance and adherence, and thus optimizing the clinical outcome. The recent introduction of yearly administration of intravenous zoledronic acid represents a powerful option in the management of patients, and is able to achieve compliance, adherence, and efficacy rates similar to those observed in clinical studies.

\section{Disclosure}

The authors report no conflict of interest in this work.

\section{References}

1. Bone HG, Hosking D, Devogelaer JP, et al. Ten years' experience with alendronate for osteoporosis in postmenopausal women. Alendronate Phase III Osteoporosis Treatment Study Group. N Engl J Med. 2004;350(12):1189-1199.

2. McClung MR, Wasnich RD, Recker R, et al. Oral Ibandronate Study Group. Oral daily ibandronate prevents bone loss in early postmenopausal women without osteoporosis. J Bone Miner Res. 2004;19(1):11-18.

3. Vertebral Efficacy with Risedronate Therapy (VERT) Study Group. Effects of risedronate treatment on vertebral and nonvertebral fractures in women with postmenopausal osteoporosis: A randomized controlled trial. JAMA. 1999;282(14):1344-1352.

4. Boonen S, Autier P, Barette M, Vanderschueren D, Lips P, Haentjens P. Functional outcome and quality of life following hip fracture in elderly women: A one-year prospective controlled study. Osteoporos Int. 2004; 15(2):87-94.

5. Rogers MJ. New insight into molecular mechanism of action of bisphosphonate. Curr Pharm Res. 2003;9(23):2643-2658.

6. Cramer JA, Amonkar MM, Hebborn A, Altman R. Compliance and persistence with bisphosphonate dosing regimens among women with postmenopausal osteoporosis. Curr Med Res Opin. 2005;21(9): $1453-1460$.

7. Huybrechts KF, Ishak KJ, Caro JJ. Assessment of compliance with osteoporosis treatment and its consequences in a managed care population. Bone. 2006(6);38:922-928.

8. Black DM, Delmas PD, Eastell R, et al. Once-yearly zoledronic acid for treatment of postmenopausal osteoporosis: HORIZON Pivotal Fracture Trial. N Engl J Med. 2007;356(18):1809-1822.

9. Reid IR, Brown JP, Burckhardt P, et al. Intravenous zoledronic acid in postmenopausal women with low bone mineral density. $N$ Engl J Med. 2002;346(9):653-661.

10. Fleish H. Bone and mineral metabolism. In: Bisphosphonates in Bone Diseases. San Diego, CA: Academic Press; 2000.

11. Lin JH, Chen IW, Deluna FA, et al. Renal handling of alendronate in rats. An uncharacterized renal transport system. Drug Metab Dispos. 1992;20(4):608-613.

12. Russell RGG, Watts NB, Ebetino FH, Rogers MJ. Mechanism of action of bisphosphonates: Similarities and differences and their potential influence on clinical efficacy. Osteoporos Int. 2008;19(6):733-759.
13. Fleish H. Bisphosphonates: Mechanism of action. Endocrine Rev. 1998;19(1):80-100.

14. Gertz BJ, Holland SD, Kline WF, et al. Studies of the oral bioavailability of Alendronate. Clin Pharmacol Ther. 1995;58(3):288-298.

15. Pedersen-Bjergaard U, Myhre J. Severe hypocalcaemia after treatment with diphosphonate and aminoglycoside. BMJ. 1991;302(6771):295.

16. Sato M, Grasser W, Endo N, et al. Bisphosphonate action. Alendronate localization in rat bone and effects on osteoclast ultrastructure. J Clin Invest. 1991(6);88:2095-2105.

17. Salo J, Lehenkari P, Mulari M, et al. Removal of osteoclast bone resorption products by transcytosis. Science. 1997(5310);276:270-273.

18. Rogers MJ, Frith JC, Luckman SP, et al. Molecular mechanisms of action of bisphosphonates. Bone. 1999;24(Suppl 5):73S-79S.

19. Green JR. Bisphosphonates: Preclinical review. Oncologist. 2004; 9(Suppl 4):S3-S13.

20. Vitte C, Fleisch H, Guenther HL. Bisphosphonates induce osteoblasts to secrete an inhibitor of osteoclast mediated resorption. Endocrinology. 1996;137(6):2324-2333.

21. Storm T, Steinichw T, Thamsborg G, et al. Changes in bone histomorphometry after long-term treatment with intermittent cyclic etidronate for postmenopausal osteoporosis. J Bone Miner Res. 1993;8(2):199-208.

22. Ebert R, Zeck S, Krug R, et al. Pulse treatment with zoledronic acid causes sustained commitment of bone marrow derived mesenchymal stem cells for osteogenic differentiation. Bone. 2009;44(5):858-864.

23. Von Knoch F, Jaquiery C, Kowalsky M, et al. Effects of bisphosphonates on proliferation and osteoblast differentiation of human bone marrow stromal cells. Biomaterials. 2005;26(34):6941-6949.

24. Plotkin LI, Weinstein RS, Parfitt AM, et al. Prevention of osteocyte and osteoblast apoptosis by bisphosphonates and calcitonin. J Clin Invest. 1999;104(10):1363-1374.

25. Giuliani N, Pedrazzoni M, Negri G, et al. Bisphosphonates stimulate formation of osteoblast precursors and mineralized nodules in murine and human bone marrow cultures in vitro and promote early osteoblastogenesis in young and aged mice in vivo. Bone. 1998;22(5): 455-461.

26. Mundy G, Garret R, Harris S, et al. Stimulation of bone formation in vitro and in rodent by statins. Science. 1999;286(5446):1946-1949.

27. Viereck V, Emons G, Lauck V, et al. Bisphosphonates pamidronate and zoledronic acid stimulate osteoprotegerin production by primary human osteoblasts. Biochem Biophys Res Comm. 2002;291(3):680-686.

28. Scutt A, Bertram P, Bräutigam M. The role of glucocorticoid and prostaglandins E2 in the recruitment of bone marrow mesenchymal cells to the osteoblastic lineage: Positive and negative effects. Calcif Tissue Int. 1996;59(3):154-162.

29. Nancollas GH, Tang R, Phipps RJ, et al. Novel insight into actions of bisphosphonates on bone: Differences in interactions with hydroxyapatite. Bone. 2006;38(5):617-627.

30. Widler L, Jaeggi KA, Glatt M, et al. Highly potent geminal bisphosphonates. From pamidronate disodium (Aredia) to zoledronic acid (Zometa). J Med Chem. 2002;45(17):3721-3738.

31. Kavanagh KL, Guo K, Dunford JE, et al. The molecular mechanism of nitrogen-containing bisphosphonates as antiosteoporosis drugs. Proc Natl Acad Sci U S A. 2006;103(20):7829-7834.

32. Lin JH. Bisphosphonates: A review of their pharmacokinetic properties. Bone. 1996;18(2):75-85.

33. Cremers SC, Pillai G, Papapoulos SE. Pharmacokinetics/ pharmacodynamics of bisphosphonates: Use for optimisation of intermittent therapy for osteoporosis. Clin Pharmacokinet. 2005;44(6):551-570.

34. Aclasta Leaflet. Pharmacological properties - Pharmacokinetic properties. Available at: http://www.ema.europa.eu/humandocs/PDFs/EPAR/ aclasta/emea-combined-h595en.pdf. Accessed Apr 16, 2010.

35. Pagani F, Francucci CM, Moro L. Markers of bone turnover: Biochemical and clinical perspectives. J Endocrinol Invest. 2005; 28 Suppl 10:S8-S13.

36. Melton LJ III, Khosla S, Atkinson EJ, O'Fallon WM, Riggs BL. Relationship of bone turnover to bone density and fractures. $J$ Bone Miner Res. 1997;12(7):1083-1091. 
37. Schett G, Kiechl S, Redlich K, et al. Soluble RANKL and risk of nontraumatic fracture. JAMA. 2004;291(9):1108-1113.

38. Dalle Carbonare L, Valenti MT, Zanatta M, Donatelli L, Lo Cascio V. Circulating mesenchymal stem cells with abnormal osteogenic differentiation in patients with osteoporosis. Arthritis Rheum. 2009;60(11): 3356-3365.

39. Eastell R, Barton I, Hannon RA, Chines A, Garnero P, Delmas PD. Relationship of early changes in bone resorption to the reduction in fracture risk with risedronate. J Bone Miner Res. 2003;18(6):1051-1056.

40. Schnitzer T, Bone HG, Crepaldi G, et al. Therapeutic equivalence of alendronate $70 \mathrm{mg}$ once-weekly and alendronate $10 \mathrm{mg}$ daily in the treatment of osteoporosis. Alendronate Once-Weekly Study Group. Aging. 2000;12(1):1-12.

41. Brown JP, Kendler DL, McClung MR, et al. The efficacy and tolerability of risedronate once a week for the treatment of postmenopausal osteoporosis. Calcif Tissue Int. 2002(2);71:103-111.

42. Reginster JY, Adami S, Lakatos P, et al. Efficacy and tolerability of oncemonthly oral ibandronate in postmenopausal osteoporosis: Two year results from the MOBILE study. Ann Rheum Dis. 2006;65(5):654-661.

43. Mellstrom DD, Sörensen OH, Goemaere S, Roux C, Johnson TD, Chines AA. Seven years of treatment with risedronate in women with postmenopausal osteoporosis. Calcif Tissue Int. 2004;75(6):462-468.

44. Watts NB, Chines A, Olszysnki WP, et al. Fracture risk remains reduced one year after discontinuation of risedronate. Osteoporos Int. 2008;19:365.

45. Reid DM, Devogelaer JP, Saag K, et al. Zoledronic acid and risedronate in the prevention and treatment of glucocorticoid-induced osteoporosis (HORIZON): A multicentre, double-blind, double-dummy, randomised controlled trial. Lancet. 2009;373(11):1253-1263.

46. McClung M, Miller P, Recknor C, et al. Zoledronic acid for the prevention of bone loss in postmenopausal women with low bone mass: A randomized controlled trial. Obstet Gynecol. 2009;114(5):999-1007.

47. Marx RE, Cillo JE, Ulloa JJ. Oral bisphosphonate-induced osteonecrosis: Risk factors, prediction of risk using serum CTX testing, prevention and treatment. J Oral Maxillofac Surg. 2007;65(12):2397-2410.

48. Bedogni A, Blandamura S, Lokmic Z, et al. Bisphosphonate-associated jawbone osteonecrosis: A correlation between imaging techniques and histopathology. Oral Surg Oral Med Oral Pathol Oral Radiol Endod. 2008;105(3):358-364.

49. Siris ES, Harris ST, Rosen CJ, et al. Adherence to bisphosphonate therapy and fracture rates in osteoporotic women. Relationship to vertebral and non vertebral fractures from 2 US Claims databases. Mayo Clin Proc. 2006;81(8):1013-1022.

50. Tosteson AN, Grove MR, Hammond CS, et al. Early discontinuation of treatment for osteoporosis. Am J Med. 2003;115(3):209-216.

51. Seeman E, Compston J, Adachi J, et al. Non-compliance: The Achilles' heel of antifracture efficacy. Osteoporos Int. 2007(6);18:711-719.

52. Hamilton B, McCoy K, Taggart H. Tolerability and compliance with risedronate in clinical practice. Osteoporos Int. 2003;14(3):259-262.

53. de Groen PC, Lubbe DF, Hirsch LJ, et al. Esophagitis associated with the use of alendronate. N Engl J Med. 1996;335(14):1016-1021.

54. Rosen CJ, Hochberg MC, Bonnick SL, et al. Treatment with onceweekly alendronate $70 \mathrm{mg}$ compared with once-weekly risedronate $35 \mathrm{mg}$ in women with postmenopausal osteoporosis: A randomized double-blind study. J Bone Miner Res. 2005;20(1):141-151.

55. Bobba RS, Beattie K, Parkinson B, Kumbhare D, Adachi JD. Tolerability of different dosing regimens of bisphosphonates for the treatment of osteoporosis and malignant bone disease. Drug Saf. 2006;29(12): $1133-1152$.

56. Hewitt RE, Lissina A, Green AE, Slay ES, Price DA, Sewell AK. The bisphosphonate acute phase response: Rapid and copious production of proinflammatory cytokines by peripheral blood $\mathrm{gd} \mathrm{T}$ cells in response to aminobisphosphonates is inhibited by statins. Clin Exp Immunol. 2005;39(1):101-111.

57. Caccamo N, Meraviglia S, Scarpa F, et al. Aminobisphosphonate activated gammadelta $T$ cells in immunotherapy of cancer: Doubts no more. Expert Opin Biol Ther. 2008;8(7):875-883.
58. Bertoldo F, Pancheri S, Zenari S, et al. Serum 25(OH)D level modulate the acute phase response associated to the first nitrogen containing bisphosphonate infusion. J Bone Miner Res. 2009;25(3):447-454.

59. Lühe A, Künkele KP, Haiker M, et al. Preclinical evidence for nitrogen containing bisphosphonate inhibition of farnesyl biphosphonate (FPP) synthase in the kidney: Implications for renal safety. Toxicology in Vitro. 2008;22(4):899-909.

60. Boonen S, Vanderschueren D, Venken K, et al. Recent developments in the management of postmenopausal osteoporosis with bisphosphonates: Enhanced efficacy by enhanced compliance. J Intern Med. 2008;264(4):315-332.

61. Conte PF, Guarnieri V. Safety of intravenous and oral bisphosphonates and compliance with dosing regimens. Oncologist. 2004;9(Suppl 4): 28-37.

62. Chen T, Berenson J, Vescio R, et al. Pharmacokinetics and pharmacodynamics of zoledronic acid in cancer patients with bone metastases. J Clin Pharmacol. 2002;43(11):154-162.

63. Skerjanec C, Berenson J, Hsu C, Major P, et al. The pharmacokinetics and pharmacodynamics in cancer patients with varying degrees of renal function. J Clin Pharmacol. 2003;42(2):1228-1236.

64. Cummings SR, Schwartz AV, Black DM. Alendronate and atrial fibrillation. N Engl J Med. 2007;356(18):1895-1896.

65. Aviles RJ, Martin DO, Apperson-Hansen C, et al. Inflammation as a risk factor for atrial fibrillation. Circulation. 2003;108(24):3006-3010.

66. Van Wagoner DR, Nerbonne JM. Molecular basis of electrical remodeling in atrial fibrillation. J Mol Cell Cardiol. 2000;32(6):1101-1117.

67. Michael Pazianas, Juliet Compston, Christopher L-H Huang. Atrial fibrillation and bisphosphonate therapy. J Bone Miner Res. 2010;25(1):2-10.

68. Harris ST, Gertz BJ, Genant HK, et al. The effect of short term treatment with alendronate on vertebral density and biochemical markers of bone remodeling in early postmenopausal women. J Clin Endocrinol Metab. 1993;76(6):1399-1406.

69. Chesnut CH 3rd, Harris ST. Short-term effect of alendronate on bone mass and bone remodeling in postmenopausal women. Osteoporos Int. 1993;3(Suppl 3):S17-S19.

70. Chennuru S, Koduri J, Bauman MA. Risk factors for symptomatic hypocalcemia complicating treatment with zoledronic acid. Intern Med J. 2008;38(8):635-637.

71. Tanvetyanon T, Stiff PJ. Management of the adverse effects associated with intravenous bisphosphonates. Ann Oncol. 2006;17(6):897-907.

72. Fraunfelder FW, Fraunfelder FT, Jensvold B. Scleritis and other ocular side effects associated with pamidronate disodium. Am J Ophthalmol. 2003;135(2):219-222.

73. French DD, Margo CE. Postmarketing surveillance of uveitis and scleritis with bisphosphonates among a national veteran cohort. Retina. 2008;28(6):889-893.

74. Ryan PJ, Sampath R. Idiopathic orbital inflammation following intravenous pamidronate. Rheumatology 2001;40:956-957.

75. Odvina CV, Zerwekh JE, Rao DS, Maalouf N, Gottschalk FA, Pak CY. Severely suppressed bone turnover: A potential complication of alendronate therapy. J Clin Endocrinol Metab. 2005;90(3):1294-1301.

76. Edwards MH, McCrae FC, Young-Min SA. Alendronate-related femoral diaphysis fracture-what should be done to predict and prevent subsequent fracture of the contralateral side? Osteoporos Int. 2010;21(4):701-703.

77. Lenart BA, Lorich DG, Lane JM. Atypical fractures of the femoral diaphysis in postmenopausal women taking alendronate. $N$ Engl J Med. 2008;358(12):1304-1306.

78. Visekruna M, Wilson D, McKienan FE. Severely suppressed bone turnover and atypical skeletal fragility. J Clin Endocrinol Metab. 2008;93(8):2948-2952.

79. Salminen S, Pihlajamaki H, Avikainen V, et al. Specific features associated with femoral shaft fractures caused by low-energy trauma. J Trauma. 1997;43(1):117-122.

80. Bertoldo F, Santini D, Lo Cascio V. Bisphosphonates and osteomyelitis of the jaw: A pathogenic puzzle. Nat Clin Pract Oncol. 2007;4(12): $711-721$. 
81. Felsemberg D, Hoffmeister B, Amling M. Onkologie: Kiefernekrosen nach hoch dosierter Bisphosphonattherapie. Deutsches Arzteblatt. 2006;103:3078-3081. German.

82. Sambrook P, Olver I, Goss A. Bisphosphonates and osteonecrosis of the jaw. Aust Fam Physician. 2006;35(10):801-803.

83. Grbic JT, Landesberg R, Lin SQ, et al. Incidence of osteonecrosis of the jaw in women with postmenopausal osteoporosis in the health outcomes and reduced incidence with zoledronic acid once yearly pivotal fracture trial. J Am Dent Assoc. 2008;139(1):32-40.

84. Recker RR, Delmas PD, Halse J, et al. Effects of intravenous zoledronic acid once yearly on bone remodeling and bone structure. J Bone Miner Res. 2008;23(1):6-16.

85. Khosla S, Burr D, Cauley J, et al. Bisphosphonates-associated osteonecrosis of the jaw: Report of a task force of the American Society for Bone and Mineral Research. ASBMR Task Force on BisphosphonateAssociated ONJ. J Bone Miner Res. 2007;22(10):1479-1491.

86. Reid IR. Osteonecrosis of the jaw - Who gets it, and why. Bone. 2009; 44(1):4-10.

87. Khan AA, Sándor GK, Dore E, et al. Canadian Association of Oral and Maxillofacial Surgeons. Canadian consensus practice guidelines for bisphosphonate associated osteonecrosis of the jaw. J Rheumatol. 2008;35(7):1391-1397.

88. Novince CM, Ward BB, McCauley LK. Osteonecrosis of the jaw: An update and review of recommendations. Cells Tissues Organs. 2009;189(1-4):275-283.

89. Black DM Cummings SR, Karpf DB, et al. Randomised trial of effect of alendronate on risk of fracture in women with existing vertebral fractures. Fracture Intervention Trial Research Group. Lancet. 1996; 348(9041):1535-1541.

90. Recker R, Lips P, Felsenberg D, et al. Alendronate with and without cholecalciferol for osteoporosis: Results of a 15-week randomized controlled trial. Curr Med Res Opin. 2006;22(9):1745-1755.

91. Binkley N, Ringe JD, Reed JI, et al. Alendronate/vitamin D3 $70 \mathrm{mg} / 2800 \mathrm{IU}$ with and without additional $2800 \mathrm{IU}$ vitamin D3 for osteoporosis: Results from the 24-week extension of a 15-week randomized, controlled trial. Bone. 2009;44(4):639-647.

92. Delmas PD, McClung MR, Zanchetta JR, et al. Efficacy and safety of risedronate $150 \mathrm{mg}$ once a month in the treatment of postmenopausal osteoporosis. Bone. 2008;42(1):36-42.

93. Harris ST, Watts NB, Genant HK, et al. Effects of risedronate treatment on vertebral and nonvertebral fractures in women with postmenopausal osteoporosis: A randomized controlled trial. Vertebral Efficacy with Risedronate Therapy (VERT) Study Group. JAMA. 1999;282(11):1344-1352.

94. Adachi JD, Saag KG, Delmas PD, et al. Two-year effects of alendronate on bone mineral density and vertebral fracture in patients receiving glucocorticoids: A randomized, double-blind, placebocontrolled extension trial. Arthritis Rheum. 2001;44(1):202-211.

95. Wallach S, Cohen S, Reid DM, et al. Effects of risedronate treatment on bone density and vertebral fracture in patients on corticosteroid therapy. Calcif Tissue Int. 2000;67(4):277-285.

96. Orwoll E, Ettinger M, Weiss S, et al. Alendronate for the treatment of osteoporosis in men. $N$ Engl J Med. 2000;343(9):604-610.

97. Boonen S, Orwoll ES, Wenderoth D, et al. Once-weekly risedronate in men with osteoporosis: Results of a 2-year, placebo-controlled, doubleblind, multicenter study. J Bone Miner Res. 2009;24(4):719-725.

98. Chestnut III CH, Skag A, Christiansen C, et al. Oral Ibandronate vertebral fracture trial in Norrth America and Europe (BONE) Effect of oral ibandronate administered daily or intermittently on racture risk in postmenopausal osteoporosis. $J$ Bone Miner Res. 2004;19(8):1241-1249.

99. Riis BJ, Ise J, von Stein T, et al. Ibandronate: A comparison of oral daily dosing versus intermittent dosing in postmenopausal osteoporosis. J Bone Miner Res. 2001;16(10):1871-1878.

100. Devogelaer JP, Brown JP, Burckhardt P, et al. Zoledronic acid efficacy and safety over five years in postmenopausal osteoporosis. Osteoporos Int. 2007;18(9):1211-1218.
101. Bauer DC, Black DM, Garnero P, et al. Change in bone turnover and hip, non spine and vertebral fracture in alendronate-treated women: The Fracture Intervention Trial Study Group. J Bone Miner Res. 2004; 19(8):1250-1258.

102. Lyles KW, Colón-Emeric CS, Magaziner JS, et al for the HORIZON Recurrent Fracture Trial. Zoledronic acid and clinical fractures and mortality after hip fracture. $N$ Engl J Med. 2007;357(18):1799-1809.

103. McClung M, Recker R, Miller P, et al. Intravenous zoledronic acid $5 \mathrm{mg}$ in the treatment of postmenopausal women with low bone density previously treated with alendronate. Bone. 2007;41(1):122-128.

104. Reid DM, Devogelaer JP, Saag K, et al. Zoledronic acid and risedronate in the prevention and treatment of glucocorticoid-induced osteoporosis (HORIZON): A multicentre, double-blind, double-dummy, randomised controlled trial. Lancet. 2009;373(11):1253-1263.

105. Van Staa TP. The pathogenesis, epidemiology and management of glucocorticoid-induced osteoporosis. Calcif Tissue Int. 2006(3);79: 129-137.

106. Jones G, Nguyen T, Sambrook PN, et al. Symptomatic fracture incidence in elderly men and women: The Dubbo Osteoporosis Epidemiology Study (DOES). Osteoporosis Int. 1994;4(5):277-282.

107. Leibson CL, Tosteson AN, Gabriel SE, et al. Mortality, disability, and nursing home use for persons with and without hip fracture: A population-based study. J Am Geriatr Soc. 2002;50(10): 1644-1650.

108. Breast International Group (BIG) 1-98 Collaborative Group. A comparison of letrozole and tamoxifen in postmenopausal women with early breast cancer. $N$ Engl J Med. 2005;353(26):2747-2757.

109. Forward DP, Cheung KL, Jackson L, Robertson JF. Clinical and endocrine data for goserelin plus anastrozole as secondline endocrine therapy for premenopausal advanced breast cancer. $\mathrm{Br} J$ Cancer. 2004;90(3):590-594.

110. ATAC Trialists' Group. Effect of an aromatase inhibitor on BMD and bone turnover markers: 2-year results of the Anastrozole, Tamoxifen, Alone or in Combination (ATAC) trial (18233230). J Bone Miner Res. 2006;21(8):1215-1223.

111. Bundred NJ, Campbell ID, Davidson N, et al. Effective inhibition of aromatase inhibitor-associated bone loss by zoledronic acid in postmenopausal women with early breast cancer receiving adjuvant letrozole: ZO-FAST study results. Cancer. 2008;112(5):1001-1010.

112. Brufsky A, Bosserman L, Caradonna R, et al. The effect of zoledronic acid on aromatase inhibitor-associated bone loss in postmenopausal women with early breast cancer receiving adjuvant letrozole: The Z-FAST study 36-month follow-up. Proceedings of the 30th Annual San Antonio Breast Cancer Symposium, San Antonio, TX, 2007 Dec 13-16.

113. Ross R, Small E: Osteoporosis in men treated with androgen deprivation therapy for prostate cancer. $J$ Urol. 2002;167(5):1952-1956.

114. Ryan CW, Huo D, Demers LM, Beer TM, Lacerna LV. Zoledronic acid initiated during the first year of androgen deprivation therapy increases bone mineral density in patients with prostate cancer. $J$ Urol. 2006;176(3):972-978.

115. Smith MR, Eastham J, Gleason DM, et al. Randomized controlled trial of zoledronic acid to prevent bone loss in men receiving androgen deprivation therapy for nonmetastatic prostate cancer. $J$ Urol. 2003;169(6):2008-2012.

116. Brown TT, Qaqish RB. Antiretroviral therapy and the prevalence of osteopenia and osteoporosis: A meta-analytic review. AIDS. 2006;20(17):2165-2174.

117. Bolland MJ, Grey AB, Horne AM, et al. Annual zoledronate increases bone density in highly active antiretroviral therapy-treated human immunodeficiency virus-infected men: A randomized controlled trial. J Clin Endocrinol Metab. 2007;92(4):1283-1288.

118. Giannini S, D'Angelo A, Carraro G, et al. Alendronate prevents further bone loss in renal transplant recipients. J Bone Miner Res. 2001; 16(11):2111-2117.

119. Shane $\mathrm{E}$, Addesso $\mathrm{V}$, Namerow $\mathrm{PB}$, et al. Alendronate versus calcitriol for the prevention of bone loss after cardiac transplantation. $N$ Engl J Med. 2004;350(22):767-776. 
120. Crawford BA, Kam C, Pavlovic J, et al. Zoledronic acid prevents bone loss after liver transplantation: A randomized, double-blind, placebocontrolled trial. Ann Intern Med. 2006;144(4):239-248.

121. Siris ES, Selby PL, Saag KG, et al. Impact of osteoporosis treatment adherence on fracture rates in North America and Europe. Am J Med. 2009;122(Suppl 2):S3-S13.

122. Gold DT, Martin BC, Frytak JR, et al. A claims database analysis of persistence with alendronate therapy and fracture risk in postmenopausal women with osteoporosis. Curr Med Res Opin. 2007; 23(3):585-594.
123. Cooper A, Drake J, Brankin E, et al. Treatment persistence with once-monthly ibandronate and patient support vs once-weekly alendronate: Results from the PERSIST study. Int J Clin Pract. 2006;60(8): 896-905.

124. Saag K, Lindsay R, Kriegman A, et al. A single zoledronic acid infusion reduces bone resorption markers more rapidly than weekly oral alendronate in postmenopausal women with low bone mineral density. Bone. 2007;40(5):1238-1243.

Drug, Healthcare and Patient Safety

\section{Publish your work in this journal}

Drug, Healthcare and Patient Safety is an international, peer-reviewed open-access journal exploring patient safety issues in the healthcare continuum from diagnostic and screening interventions through to treatment, drug therapy and surgery. The journal is characterized by the rapic reporting of reviews, original research, clinical, epidemiological and
Dovepress

post-marketing surveillance studies, risk management, health literacy and educational programs across all areas of healthcare delivery. The manuscript management system is completely online and includes a very quick and fair peer-review system. Visit http://www.dovepress.com/ testimonials.php to read real quotes from published authors.

Submit your manuscript here: http://www.dovepress.com/drug-healthcare-and-patient-safety-journal 